\title{
Consistent Condom Use and Preference of HIV Risk Preventive Interventions among Undergraduate University Students in Southern Ethiopia: A Cross Sectional Study
}

\section{Terefe Gelibo ${ }^{1 * \dagger}$ and Antehun Alemayehu ${ }^{2 \dagger}$}

${ }^{1}$ Department of Public Health, School of Medicine and Health Sciences, Addis Ababa Science and Technology University, Ethiopia

${ }^{2}$ Schools of Medicine, College of Health Sciences and Medicine Wolaita Sodo University Wolaita Sodo, Ethiopia

'Equal contributors

\begin{abstract}
Introduction: To reduce HIV (human immunodeficiency virus) infection, attention has been focused recently on the promotion of the "ABCs" (being abstinent, remaining faithful to one sexual partner, and using condoms consistently). In Ethiopia, despite the mushrooming number of students in the higher learning institutions, students were not equipped with the necessary skills to protect themselves from HIV infection.
\end{abstract}

Methods and materials: This cross-sectional study was aimed to identify consistent condom use and students preference. A total of 770 students were sampled and selected using the principle of proportional to size allocation method. Then, students were selected from each department by simple random sampling technique using lists of students as sampling frame. Data were collected using structured self-administered questionnaire, focus group discussion guide and in depth interviews check lists as tools. Statistical tests were employed wherever necessary at the significance level of 0.05 .

Result: About $50.4 \%$ of students were used condom during sexual intercourse in the last 12 months, $33.2 \%$ of them used condom consistently. Male students preferred condom use while female students preferred to be sexually abstinent and being faithful with single regular partner. Students from urban residents were 8.3 times more likely to use condom consistently than those from rural areas. Students who had monthly income were 6 times more likely to use condoms consistently than their counter parts.

Conclusion and recommendation: Less than one third of students use condom consistently and condom preference varies by gender among university students To respond proactively to the current needs of the target group based on evidence and scientific behavioral theories and proven interventions, the university needs not relying on any single intervention approach, rather using a combination of behavioral, structural and biomedical interventions coordinated to achieve maximum effect.

Keywords: Consistent; Condom; HIV; Interventions; Students; Undergraduate; University

\section{Introduction}

It is over 30 years since the first cases of AIDS [acquired immune deficiency syndrome] were identified [1]. HIV pandemic remains the most serious of infectious disease challenges to public health. There is still neither a vaccine nor cheap, assured and effective treatment for HIV/AIDS [1,2]. The disease deprives countries, communities, and households of their strong, productive people [1]. Currently more than 33.2 million people are living with the virus worldwide and Africa, and in particular Sub-Saharan Africa, is at present in the "eye of the storm" [1-3].

In Ethiopia, HIV epidemic has penetrated even the hard-to-reach rural areas. However, with the existing socio-cultural diversity of Ethiopia, the pattern and distribution of HIV widely varies by region, place of residence and sex [4]. Even though the virus affects all social sectors of the population, the epidemic among adolescents is the fastest growing partly because of young people's vulnerability and because of low use of preventive services [5]. The young never married females carry the greatest risk of HIV infection because of both biological, cultural factors. Often they form sexual relationships with men who are on average ten years older and as the girls are unlikely to have had any training or experience in sexual negotiation skills, and are especially vulnerable in situations with older men where age, wealth, physical strength and other power dynamics put them at a disadvantage $[4,6]$.
The EDHS 2005 confirmed the widely-held belief that girls start having sex earlier than boys [4].

Universities in the high prevalence countries of sub Saharan Africa significant proportion of their students and staff may be infected with HIV [7]. Therefore, universities are one of priority targets for promoting and enhancing healthy sexual behavior among students [7,8]. University students are youths who are impressionable, may not have adequate or consistent income, and are living without consistent adult supervision for first time in their lives. All these compounded with peer pressure makes them highly vulnerable to HIV [7]. Unprotected sexual practice patterns among university students lags behind knowledge and attitude towards prevention of STDs and condom use [6]. A number of studies

*Corresponding author: Terefe Gelibo, Department of Public Health, Schoo of Medicine and Health Sciences, Addis Ababa Science and Technology University, P.O. Box 16417, Addis Ababa, Ethiopia, Tel: 251912139705; E-mail: mamater.1986@gmail.com

Received February 19, 2015; Accepted March 17, 2015; Published March 25, 2015

Citation: GeliboT, Alemayehu A (2015) Consistent Condom Use and Preference of HIV Risk Preventive Interventions among Undergraduate University Students in Southern Ethiopia: A Cross Sectional Study. J AIDS Clin Res 6: 442. doi:10.4172/2155-6113.1000442

Copyright: ( 2015 GeliboT, et al. This is an open-access article distributed unde the terms of the Creative Commons Attribution License, which permits unrestricted use, distribution, and reproduction in any medium, provided the original author and source are credited. 
have showed that HIV/AIDS risk behaviors have progressively been on increase and being the problem of students in the higher education institutions in Ethiopia [9-11]. In general, students are one part of the most vulnerable groups in the country particularly college and precollege students: in recent years a number of new training and higher learning institutions have been opened. These sites and their student populations have not been studied, but there is some circumstantial evidence suggesting the existence of widespread unsafe sexual practices [12]. All schools including colleges and Universities will have HIV/ AIDS information centers. At Wolaita Sodo University, responses in the form of policies and programmes have been implemented over the past two decades to various extents at different levels but factors associated with consistent condom use and preference of students on HIV preventive interventions within institutions has not been known adequately and this has constrained planning processes. So this study was aimed to identify Predictors of consistent condom use and students preference on preventive interventions among WSU students.

\section{Methods}

\section{Study setting and period}

A cross-sectional study design was conducted in Wolaita Sodo University from May to June, 2010. Wolaita Sodo University is one of recently established public university in Ethiopia. The University has five faculties and two schools i.e. faculty of health science, faculty of natural science, faculty of social science, faculty of agriculture, faculty of business economics, school of law and school of technology. The university had total of 6540 regular undergraduate students. All undergraduate students who registered in 2010/2011 academic year were taken as study population.

\section{Sample size and sampling procedure}

The sample size was determined by taking $64.5 \%$ of expected prevalence for consistent condom use reported by the study among Jimma university students [9], assuming 5\% margin of error and $95 \%$ confidence level, design effect of 2 and $10 \%$ for non-response rate. The calculated sample size was 770 . Numbers of students in each study year within the departments were selected using the principle of proportional to size allocation method. Then, students were selected from each department by simple random sampling technique using lists of students as sampling frame.

\section{Measurement}

Data were collected using self-administered structured questionnaire under the supervision of the supervisors and principal investigator, focus group discussion and in-depth interviews were also conducted to generate qualitative data. Seven Focus Group Discussions (FGDs) ( 3 with males and 4 with female students) were conducted with each consisting of 6-12 students. For in-depth interview university officials were selected purposefully as key informants. The data were collected on preference of HIV risk preventing interventions and consistent condom use and the independent variables including socio demographic and socioeconomic variables; HIV/AIDS transmission and prevention related knowledge, communication of children with parents about sexual issues and sexual behaviors. Consistent condom use was measured by asking subjects who reported sexual activity in the last 12 months, the criterion variable in this analysis, was assessed with the question, "How often did you use a condom when you had vaginal sex in the last 12 months?" The question was ranging from "sometimes" to "always" use condoms during sexual intercourse. Students who reported always using condoms during sexual intercourse were classified as consistent condom users, whereas the others were classified as infrequent condom users.

\section{Statistical analysis}

The data were coded, edited and entered, cleaned and analyzed using SPSS for windows version 16. Statistical analysis has three steps: first association was done between potential predictors of consistent condom use using Pearson's chi-square and 95\% confidence intervals were calculated to show bivariate association. Next, to identify the independent contribution of each variable on consistent condom use, multivariable logistic regression models were used. Adjusted odds ratio, and confidence intervals were calculated to assess the association between independent variables and consistent condom use. Finally, it was evaluated that variables identified as associated $(\mathrm{p}<0.05)$ with dependent variable in the multivariate logistic regression analysis were used to predict consistent condom use. The qualitative data were transcribed into English language verbatim, read critically and essential themes were identified. Then ideas related to each team were color coded. Then ideas were organized into concepts and presented using narratives. The result is presented in tri-angulations with the quantitative survey using subjects verbatim as illustrations.

\section{Data quality control}

The collected data were reviewed and checked for completeness and relevance by the supervisors and principal investigator each day and was checked, coded and entered in to computer and cleaned before analysis. Investigators discussion guide was cross checked between the note takers and the principal investigator then transcribed into hand written English transcript

\section{Ethical issues}

Letter of cooperation was obtained from Wolaita Sodo University, Research and Publication Office; Informed consent was obtained from each study subjects prior to the administration of questionnaire after the purpose of the study was explained to respondent. Confidentiality of information was maintained at all levels by the research team.

\section{Results}

\section{Socio-demographic and Socioeconomic Characteristics}

Out of the total 770 sample, most (749) of the selected students participated in the survey making a response rate of $97.3 \%$. The participation of by their sex indicated that there were $532(71.0 \%)$ of male and 217 (29.0\%) of female students. Majority of participants were selected from five faculties 194 (25.9\%) Natural science, 154 (20.6\%) Business economics, 144 (19.2\%) Social Science, 103 (13.8\%) Agriculture and Rural development, 76 (10\%) were from Health Science. By their academic year $47.5 \%, 20.4 \%$ and $32.0 \%$ were Year I, II and III students respectively. Most of the students 733 (97.9\%) were living in campus. Self-reported academic performance of participants indicated that $382(51.0 \%)$ were having at least average, $250(33.4 \%)$ below average result and the rest were ten tops based on the current academic status.

The mean $( \pm$ SD) age of the respondents was $20.9( \pm 1.5)$ years with minimum of 18 and maximum 35 years of age and $41.1 \%$ of them were less than 20 years of age where as $58.9 \%$ of respondents were 20 and above years of Age.

By their ethnicity the majority of students were Amhara 181 (24.2\%), Hadiya 129 (17.2\%) and Oromo 128 (17.1\%) respectively. 
A greater proportion of the participants were Orthodox Christian $368(49.1 \%)$, followed by protestant 261 (34.8\%) and Muslim 107 (14.3\%) by their religion. When asked for their frequency of church or mosque attendance per month, $453(60.5 \%)$ participants responded attendance of church/mosque more than twice a month and the rest 296 (39.5\%) reported twice or less per month. By their previous place of residence, 379 (50.6\%) were from Rural area, 370 (49.4\%) were from urban areas.

Regarding economic status of students, 468 (61.9\%) of participants reported to have monthly income from any source and the rest did not. The major sources reported by the respondents were from their parents but when asked for financial sources other than parents/university, the great majority 83 (65.4\%) get monthly income from their boy/ girlfriends followed by $28(22.0 \%)$ from non-regular sexual partners. From the participants 387 (51.7\%) classified their family socioeconomic status as average, $261(34.8 \%)$, below average and 101 (13.5) classified as above average.

\section{Condom use}

About half 201 (50.4) of students were used condom during sexual intercourse in the last 12 months prior to the survey and the rest 198 (49.6) were not used condom during sexual intercourse in the last 12 months prior to survey. Of the users $52.2 \%$ used sometimes, $33.2 \%$ used always and $14.6 \%$ used most of the time. There was significant association between condom use and gender of students. Male students were 2.9 (CI: $1.8,4.8$ ) times more likely to use condom than female students (Figure 1).

The majority $139(66.8 \%)$ of participants reported infrequent condom use whereas the rest 78 (33.2\%) reported consistent condom use during sexual intercourse in the last 12 months. The reasons given for infrequent use of condom were reported as trust on their partner, partner refusal, in love with their partner, dislike condom, condom reduces pleasure, condom not readily available, and others $(33.0 \%$, $18.5 \%, 17.4 \%, 14.0 \%, 9.2 \%, 5.5 \%, 2.3 \%$ ) respectively (Table 1 ).

\section{Students preference and future plans on HIV risk preventive interventions}

Pertaining to the students' preference and their future plan on HIV risk preventive interventions, $44.7 \%$ of the students preferred being faithful to single regular partner, $35.2 \%$ preferred abstinent from sexual intercourse and the rest (20.1\%) preferred correct and consistent use of condom. There was significant association between sex and preference of HIV preventive services. Male students were 2.4 (95\% CI1.2, 3.8) times more likely to prefer correct and consistent condom use than female students. On the other hand female students were $3.7(255 \%$ CI $2.3,5.7)$ times more likely to prefer being faithful to single regular partner than male students. But in the focus group discussion, most of the discussants believed that the best way of avoiding HIV/AIDS was through the practice of faithfulness between partners.

Pertaining to students' preference on HIV preventive services in the university community, the majority, $32.8 \%$ of respondents preferred youth information center/AIDS resource center, $32.3 \%$ preferred IEC [Information education communication] on STI including HIV/ AIDS through the use of medias at regular bases, $15.0 \%$ preferred condom promotion and distribution, $12.4 \%$ preferred partner relation guidance and the least, $7.5 \%$ preferred sex education in their order of importance as HIV preventive interventions. University level HIV preventive service provider preference varies from highest $47.8 \%$ youth the same sex to the least $8.1 \%$ adult of the same sex. Preference of HIV preventive service provider had significant association with gender of the respondents $(\mathrm{x} 2=52.53, \mathrm{p}<0.001)$. Males prefer condom promotion ( $18 \%$ male vs. $3 \%$ female) and provider of any provide could be $(18.3 \%$ male vs. $3.7 \%$ female). On the other hand female students prefer IEC on SRH including HIV/AIDS and youth health information center (70.1\% females, $38.4 \%$ male) and youth of the same sex as service provider (64.6\% female vs. $32.5 \%$ male). On students future plan for HIV preventive services the majority of students (84.1\%) planned to be tested if VCT services were available while the rest were not willing to be tested due to different reasons such as fear of stigma. The discussants added that the challenges and obstacles prevent students

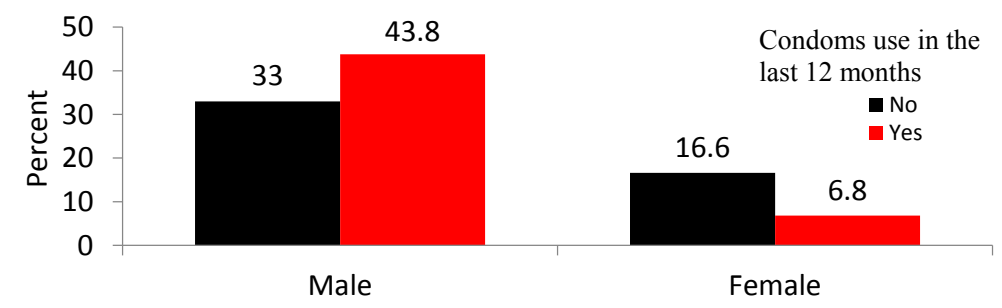

Figure 1: Proportions of students who used condom during sexual intercourse in the last 12 months by gender, Wolaita Sodo University Students, June, 2010.

\begin{tabular}{|c|c|c|c|}
\hline \multicolumn{2}{|l|}{ Variables } & Number & Percent \\
\hline \multirow{2}{*}{ Frequency of condom use $(n=253)$} & Inconsistent & 169 & 66.8 \\
\hline & Consistent & 84 & 33.2 \\
\hline \multirow{6}{*}{ Reasons not to use condoms in the last intercourse $(n=310)$} & Condoms were not available & 17 & 5.5 \\
\hline & I dislike condoms & 45 & 14.5 \\
\hline & My partner refused & 52 & 16.8 \\
\hline & I trusted my partner & 107 & 34.5 \\
\hline & It reduces pleasure & 47 & 15.2 \\
\hline & Other & 36 & 11.6 \\
\hline \multirow{2}{*}{ Condom use after having alcohol $(n=214)$} & Yes & 166 & 78.3 \\
\hline & No & 46 & 21.7 \\
\hline
\end{tabular}

Table 1: Sexual practice and condom use among students of Wolaita Sodo University, 2010. 
Citation: GeliboT, Alemayehu A (2015) Consistent Condom Use and Preference of HIV Risk Preventive Interventions among Undergraduate University Students in Southern Ethiopia: A Cross Sectional Study. J AIDS Clin Res 6: 442. doi:10.4172/2155-6113.1000442

Page 4 of 5

\begin{tabular}{|c|c|c|c|c|c|}
\hline \multirow{2}{*}{\multicolumn{2}{|c|}{ Predictor variables of consistent condom use }} & \multicolumn{2}{|c|}{ Condom use in last 12 month } & \multirow{3}{*}{$\begin{array}{c}\text { Crude OR }(95 \% \mathrm{Cl}) \\
0.6(0.3,1.1)\end{array}$} & \multirow{3}{*}{$\begin{array}{c}\text { Adjusted OR (95\% CI) } \\
0.3(0.2,1.4) \\
\end{array}$} \\
\hline & & \multirow{2}{*}{$\begin{array}{c}\text { Infrequently } \\
47.6\end{array}$} & \multirow{2}{*}{$\begin{array}{c}\text { Consistently } \\
20.2\end{array}$} & & \\
\hline Condor (N-252) & Male & & & & \\
\hline Gender (IN=253) & Female & 19.2 & 13.0 & 1.00 & 1.00 \\
\hline \multirow{2}{*}{ Drink Alcohol(N=253) } & No & 12.8 & 24.1 & $2.5(1.5,4.5)^{\star}$ & $0.8(0.3,2.6)$ \\
\hline & Yes & 54.0 & 9.1 & 1.00 & 1.00 \\
\hline \multirow{2}{*}{ Have monthly income $(\mathrm{N}=253)$} & No & 22.9 & 3.2 & 1.00 & 1.00 \\
\hline & Yes & 43.9 & 30.0 & $4.9(2.2,10.9)^{\star}$ & $6.0(2.9,12.4)^{\star}$ \\
\hline \multirow{2}{*}{ Faculty of respondents $(\mathrm{N}=253)$} & Non health & 77.1 & 5.5 & 1.00 & 1.00 \\
\hline & Health & 4.7 & 27.7 & $4.0(2.2,9.5)^{*}$ & $4.0(1.6,10.1)^{\star}$ \\
\hline \multirow{2}{*}{ Place of previous resident $(\mathrm{N}=253)$} & Rural & 27.6 & 2.4 & 1.00 & 1.00 \\
\hline & Urban & 28.2 & 30.8 & $11.1(6.2,16.3)^{*}$ & $8.3(6.2,10.9)^{*}$ \\
\hline \multirow{2}{*}{ Communication with parents about sexual issues $(N=253)$} & Poor & 29.0 & 5.5 & 1.00 & 1.00 \\
\hline & Better & 37.8 & 27.7 & $2.0(1.2,3.9)^{*}$ & $1.3(0.5,3.3)$ \\
\hline \multirow{2}{*}{ Age(yrs) of $1^{\text {st }}$ Sexual intercourse $(N=253)$} & $\leq 18$ years & 10.0 & 5.0 & 1.00 & 1.00 \\
\hline & $>18$ years & 47.0 & 28.2 & $4.1(1.6,10.9)^{*}$ & $1.4(0.9,2.3)$. \\
\hline
\end{tabular}

*Statistically significant.

Table 2: Unadjusted and Adjusted Odds ratios and (95\% confidence intervals) from logistic regression showing effects of selected Characteristics (predictor variables) on the likely hood of consistent condom use in the last 12 month among Wolaita Sodo University Students.

from getting VCT service include lack of trust on service providers, lack of confidence in the quality of treatment and counseling, fear of being identified by somebody and lack of privacy.

\section{Factors associated with consistent condom use}

Bivariate and multivariable logistic regression analysis was used to calculate odds ratios and corresponding $95 \%$ confidence intervals for the predictors of consistent condom use. Concerning predictors of condom use in the bivariate analysis, consistent condom use in the last 12 months was associated with having monthly income, alcoholic non intake, being faculty of health student, urban place of previous residence, age of 1 st sexual intercourse $>18$ years, and better communication with their parents about sexual issues (Table 2).

When adjusted for other confounders in multivariable logistic regression analyses, only three variables, being faculty of health science student, having monthly income and coming from urban area were the potent predictors of consistent condom use. Students from health science faculties were 4 times more likely to use condom consistently than those from non-health faculties and students from urban residents were 8.3 times more likely to use condom consistently than those from rural areas. Students who had monthly income were 6 times more likely to use condoms consistently than their counter parts (Table 2).

\section{Discussion}

The data show that consistent condom use found to have an association with socio demographic and economic and behavioral characteristic among university students.

Half of the surveyed students did not used condom during intercourse. There was significant association between condom use and gender of students. Male students were 3.3 times more likely to use condom than female students. This fact was agreed with a study done among university students in Madagascar [13], male students use condom more than female students. This suggests that condom use among female student was uncommon. Furthermore, the use of another contraceptive method could have led female students to abandon the use of condoms. Consistent condom use was reported by only $33.2 \%$ of the students. This was smaller than a study among Jimma university students where $64.5 \%$ used condom consistently
[9] and a study among university students in Eastern China indicated that frequent [always] condom use was reported by about $40 \%$ of both men and women [14]. This suggests that consistent condom use in this study remain low. This may be due to different reasons associated with condom use. For instance, the main reasons given for infrequent use of condom among university student in this study were trust on their partner, partner refusal, in love with their partner, condom dislike; condom reduces pleasure, condom not readily available. These imply that students' low risk perception to HIV infection due to false sense of security, power imbalances in condom negotiation skills and absence of regular condom promotion services in the university community.

On the multivariable logistic regression analyses gender was not significantly associated with consistent condom use among university students. This contradicts with a study among university students in Madagascar [13] in which gender was the main predictors of consistent condom use.

Students from urban place of previous residence were 8.3 times more likely to use condom consistently than those from rural areas. A Study among Rwandan youth supports this fact that consistent condom use was associated with urban residence [15]. The possible explanation could be that knowledge and information on condom use might lead students to use condom consistently. Students from urban area could have access and information on how to use of condom and risks associated with infrequent use of condom. This study revealed that there were low condom uses in general and consistent use of condom in particular among university students [male than of female mention condom use as a way of avoiding HIV/AIDS]. Students' preference on HIV/AIDS risk preventing services varies by gender. Male students preferred condom use while female students preferred to be sexually abstinent and being faithful with single regular partner. To respond proactively to the current needs of the target group based on evidence and scientific behavioral theories and proven interventions, the university needs not relying on any single intervention approach, rather using a combination of behavioral, structural and biomedical interventions coordinated to achieve maximum effect.

\section{Acknowledgment}

We would like to forward our gratitude to the supervisors, respondents and Wolaita Sodo University community. 
Citation: GeliboT, Alemayehu A (2015) Consistent Condom Use and Preference of HIV Risk Preventive Interventions among Undergraduate University Students in Southern Ethiopia: A Cross Sectional Study. J AIDS Clin Res 6: 442. doi:10.4172/2155-6113.1000442

\section{References}

1. Tony B (2003) HIVIAIDS has changed the world. The Acp-Eu Courier, 197.

2. UNAIDS, WHO (2007) AIDS epidemic Update.

3. UNAIDS (2006) Improving parameter estimation, projection methods, uncertainty estimation, and epidemic classification. Report of a meeting of the UNAIDS Reference Group on Estimates, Modelling, and Projections, Prague, Czech Republic, 29 Nov-1 Dec.

4. CSA, ORC Macro (2006) Ethiopia Demographic and Health Survey 2005. Central Statistical Agency and ORC Macro.

5. Georges G, Nyovani JM (2007) HIVIAIDS and Sexual-Risk Behaviors among Adolescents: Factors influencing the use of condoms in Burkina Faso. Afr J Reproductive Health 11: 182-196.

6. Ethiopia HIVIAIDS Prevention and Control Office [HAPCO], Global AIDS Monitoring and Evaluation Team [GAMET] (2008) HIVIAIDS in Ethiopia an Epidemiological Synthesis. World Bank Global HIVIAIDS Program.

7. Association of African Universities [AAU] (2004) An HIV/AIDS Toolkit for Higher Education Institutions in Africa. Johannesburg, South Africa.

8. Njikam née Savage (2006) Risky Sexual Behavior, Sexually Transmitted Infections, HIVIAIDS and Health Promotion among Students in the University of Douala. African Population Studies 20: 53-67.
9. Tefera B, Challi J, Yoseph M (2004) Knowledge, Attitude and Practice about HIVIAIDs, Voluntary Counseling and Testing among students of Jimma University, Jimma Zone, Southwest Ethiopia. Ethiop J Health Sci 14: 43-53.

10. Fitaw Y, Worku A (2002) High risk sexual behavior and pattern of condom utilization of the Gondar College of Medical Sciences students, North Western Ethiopia. Ethiop J Health Dev 16: 335-338.

11. Taffa N (1998) Sexual activity of out-of-school youth, and their knowledge and attitude about STDs and HIVIAIDS in Southern Ethiopia. Journal of health Dev 12.

12. Mirgissa K (2008) HIV Program in Higher Training Institutions in Ethiopia: Key Highlights and Ways Forward.

13. Rahamefy $\mathrm{OH}$, Rivard $M$, Ravaoarinoro $M$, Ranaivoharisoa $L$ Rasamindrakotroka AJ, et al. (2008) Sexual behavior and condom use among university Students in Madagascar. SAHARA J 5: 28-35.

14. Qiaoqin M, Masako O, Liming C, Xiaohong K, Xu G, et al. (2009) Behavioral and psychosocial predictors of condom use among university students in Eastern China. AIDS Care: Psychological and Socio-medical Aspects of AIDS/ HIV 21: 249-259.

15. Babalola S, Awasum D, Quenum-Renaud B (2002) The correlates of safe sex practices among Rwandan youth: a positive deviance approach. African Journal of AIDS Research 1: 11-21. 